\title{
Feature
}

\section{0 years of The Journal of Agriculture of the University of Puerto Rico 1917 - 2017, Part 2}

\author{
Lorelei Albanese ${ }^{1}$ and Wanda I. Lugo ${ }^{2}$
}

J. Agric. Univ. P.R. 102 (1-2):129-132 (2018)

Editor's Note: We applaud the many scientists who authored notable articles published in The Journal of Agriculture of the University of Puerto Rico from 1967-2017. See portal "revistas.upr.edu" to access the online index of JAUPR for articles published in the past 100 years to today.

The Journal of Agriculture of the University of Puerto Rico 1967 - 2017

As the second half of its centennial unfolded, The Journal of Agriculture of the University of Puerto Rico was basking in the glory of the island's "golden age," which spanned 1950 to 1970 when research reached new heights. Under Operation Bootstrap, the Agricultural Experiment Station embarked on industrializing agriculture. That historic endeavor culminated in the establishment of the Rum Pilot Plant and the Food Technology Laboratory (FTL), inaugurated in 1953 and 1957, respectively. While scientists at the experiment station's rum plant and food lab published their own series of papers, research activities in both specialties were also documented in the Journal. In the years from 1967, the Journal published diverse articles related to rum that ran the gamut from identifying compounds in rum concentrates with chromatography-mass spectrometry to using sugar cane waste (bagasse) in beef cattle diets to cut high feeding costs.

The expansive urbanizing of Puerto Rico in the $60 \mathrm{~s}, 70 \mathrm{~s}$ and $80 \mathrm{~s}$ caused a drastic decline in agriculture and significant growth in manufacturing, making it essential for rum production and food processing to keep agriculture in the game. Food research, undertaken at FTL and

${ }^{1}$ English-language Editor, Agricultural Experiment Station, University of Puerto Rico-Mayagüez Campus.

${ }^{2}$ Editor, Agricultural Experiment Station, University of Puerto Rico-Mayagüez Campus. 
published in the Journal, reflected a wide range of topics, including: techniques of hot-water peeling of frozen green bananas, pulp extraction procedures for mango, soursop and tamarind; developing nectars and marmalades of different fruits, preparing flour and chips from farinaceous crops, assaying canned fruit juices and nectars for vitamin content, processing and canning of pigeon peas, freezing of green plantain slices and mashed tanniers, and developing freeze-dried products. Some of the methods developed at FTL were transferred to the canning industry, adding value to agricultural products. As the popularity of convenience foods increased among Puerto Ricans, researchers studied safe and sound storage.

With its R\&D program, the experiment station aimed to improve agricultural production, a formidable goal because local farmers were not able to meet consumer demand. Indeed, in the 80s, Puerto Rico imported well over 50 percent of the fruits and vegetables consumed on the island, an impediment to developing a successful food processing industry. (Today food imports, including meat, dairy, fish and produce, total more than 80 percent.)

Industries such as cattle ranching and poultry farming were also hampered by competition from lower-cost imports. Dairy farming stood out for its extraordinary growth from 1945 to 1965, but slacked off thereafter, primarily because the farms were not efficient enough to make expansion economically feasible. One deterrent was high feeding costs and a second, the cost of breeding replacement animals. During the $60 \mathrm{~s}$ and $70 \mathrm{~s}$, and even into the $21^{\text {st }}$ century, studies proliferated on advances in improving forages, such as pasture management, production of tropical grasses, feeding systems, nutritive values and digestibility of forage, silage and other livestock feed.

At the same time, agriculture became more technical, and new strategies to improve efficiency in crop production as well as cattle ranching fed the Journal. Sugarcane still occupied a prominent place, despite its decline. More than 80 articles related to sugar were published in the Journal between 1970 and 1985. Challenged by an incipient rice industry, the experiment station carried out research on rice, disseminating those results in the Journal. Research, however, was most notable in farinaceous crops (plantains, bananas, yams, yautía), as well as in coffee, pigeon peas, beans, pineapple and vegetables, generating a large number of articles for the Journal. In animal science, studies on laying hens, especially regarding nutrition, stood out and so did those on parasitology. A new initiative to use drip irrigation in planting vegetables on the south coast prompted the Juana Díaz Substation to evaluate this practice, which benefitted the region's farmers. Many articles on the subject appeared in the Journal in the 1980s. 
As the sun set on sugar, many crops traditionally planted in the mountains (especially the farinaceous) were moved to coastal lands, thus increasing research in these areas. The last two decades of the 20th century saw the Journal publish numerous articles on farinaceous, vegetables, beans, coffee, fodder and animal nutrition. Studies on cattle and small ruminant nutrition examined the nutrient digestibility of tropical grasses and hays, silage from high protein white corn and mixtures of pigeon peas and guinea-grass hay for goats. Recurring topics highlighted irrigation, fertilization (with inorganic fertilizers and chicken manure) and the evaluation of agronomic practices and varieties.

Researchers reported new records of insects, conducted insect surveys and worked on entomological taxonomy. Detection and control of diseases, nematodes and insects in different crops, as well as weed control continued to fill the Journal's pages. Similarly, studies on the biological control of pests using parasitoids, entomopathogenic fungi and plants such as Mucuna, have been published. The development of a technique using hot water to destroy the larvae of Anastrepha obliqua was significant in the successful marketing of mangoes.

The 21st century has seen vast diversification in agricultural research. The development of novel varieties, changes in environmental laws, consumer preferences and farmer profiles; increased agricultural inputs and the entry of new diseases and pests affecting important crops have forced us to explore fresh alternatives. Using laboratory methods at the molecular level while injecting innovative technologies in every field is moving us into other areas of research, reflected in recent publications. Gene sequencing to identify and characterize pathogens harmful to plants and improve crop production appear as well as projects evaluating the use of genetics to boost the development of productive traits in cattle.

The Journal has published research on organic farming, the sustainability of ecosystems and conserving resources, particularly in protecting the resource of water, including a proposal for a regulatory approach to prevent nutrient impairment of Puerto Rico's reservoirs.

And the Journal continues to evolve. During its first 70 years, only articles in English were published. But by 1988, articles in Spanish were accepted to stimulate a greater flow of manuscripts. However, a substantial decrease in the number of researchers at the experiment station, coupled with the proliferation of new specialized science journals over the years resulted in fewer manuscripts for the Journal. As a result, we reduced the number of issues published in each volume from four to two. Since then, we have taken other measures to stimulate the submission of manuscripts, such as the creation of new sections including 'Notes', 'Cultivar and Germplasm Releases' and 'Features'. 
In keeping with the technological advances, the Journal entered the UPR Journals project in 2016, allowing us to upload much of the publication's content to the Internet. Initially, we sought to make the content of the magazine available electronically; more than 60 volumes were already online for the Journal's centennial. Today, the entire 100 years of publication is online; close to 3,000 thousand research reports. Gradually we will begin a second stage of the project with electronic administration of the manuscripts. For more than a century, our journal has definitely been effective in disseminating scientific information about agriculture in Puerto Rico and elsewhere wherever the Journal lands in the world. 